tonous and dull, and similarly the arrangement of the old class of museums was such as to give the least amount of instruction beyond the bare fact of the existence of given objects.

Large national collections should be exhaustive, and this necessitates a multiplicity of objects, but that should not preclude a scheme of arrangement which would make the specimens yield the maximum amount of information they are capable of giving. The Indian Museum affords an example of the worst style of museum arrangement.

The public has a right to expect that national specimens shall be arranged in the best possible manner, and the Government should appreciate the fact that museums, if properly conducted, afford the most interesting and vivid means for conveying instruction.

\section{AlFRED C. HADDON.}

\section{THE APPLICATIONS OF GEOMETRY TO PRACTICAL LIFE. ${ }^{1}$}

THERE is scarcely any branch of modern science which has of recent years made such progress as geometry : there is certainly no branch over the purport of which there is so much obscurity or has been so much discussion. On the one hand, geometry, like most sciences, was born of a practical need. The Egyptians, ${ }^{2}$ an eminently practical people, were not interested like the Greeks in the properties of the circle for the circle's own sake, but they wanted an art to measure the capacity of their barns and the size of their haystacks, and to plan out their pyramids and great buildings. But above all they were landowners, and to sell property they required to measure land - to measure it in square feet, and not by the time that a yoke of oxen would take to plough it, which was not always an exact or convenient test. So the Egyptians invented land-measuring or surveying, and termed it geometry, and the geometricians they called rope-stretchers. Thus in the doggrel of an old textbook :-

\section{To teach weak mortals property to scan}

Down came geometry and formed a plan.

The origin and the early applications of geometry were thus essentially due to the needs of practical life.

On the other hand, the Egyptians, having satisfied their immediate wants, left geometry uncultivated, and by not pursuing it on purely theoretical grounds, failed to convert it into that great instrument of investigation which in the end was to master the mystery of the heavens, guide the mariner across the trackless sea, or help the engineer to span the St. Lawrence or Douro.

The next stage in the development of geometry was left to the Greeks, for whom to apply geometry to practical purposes would have been to debase it. They studied geometry for its own sake, much as some of our friends to-day study metaphysics, only, it seems to me, they did it to more purpose. They recognized in geometry a great instrument for sharpening the intellect, and they made it the basis for a sound education. A proposition was to them a delight in itself, and to deduce a new one a distinct intellectual advance. Thus they had the proverb, "A figure and a stride : not a figure and sixpence gained."

I cannot emphasize this purely theoretical tendency of Greek geometry better than by a tale which is told of Euclid by Stobæus :-A youth, who had begun to read geometry with Euclid, when he had learnt the first pro-

' A thirty minutes' Probationary Lecture, delivered at Gresham College, on Friday, December 12, 1890 , by Prof. Karl Pearson.

The historical facts of this lecture are chiefly drawn from two excellent books-Gow's "History of Greek Geometry," and Ward's "Lives of the Professors of Gresham College."

$$
\text { NO. I IO8, VOL. 43] }
$$

position inquired, "What do I get by learning these things ?" So Euclid called his slave and said, "Give him threepence, since he must gain out of what he learns."

I have said enough perhaps to indicate how the two tendencies of modern geometry, and indeed of the whole of modern science, date back to the very beginnings of scientific activity--to the practical Egyptians, whose horizon was bounded by the immediate needs of life, and to the dreamy metaphysics-loving Greeks, who despised practical applications. There are few teachers of geometry who will not have felt at times the burden of these two tendencies. The great mass of material in the form of published papers on higher geometry, many of which can only be understood by the initiated few, and some of which have probably never been read except by their writers-this weighs at times upon the mind and makes one, without despairing of science, cry, "Cui bono? For whose good? How can this help the progress of mankind?" On the other hand, how the listless student, bent on struggling through life with the least expenditure of intellectual energy-how he calls up the spirit of the Greek, when he languidly asks his teacher after lecture, "What is the use of this? I've got the result in "The Engineer's Pocket-book.'" For him the insight to be gained by seeing the how and why of a process is of no importance, and the fingers tingle to hand him threepence that he may at least gain something by attending our lectures.

It is not my purpose now to trace these practical and theoretical tendencies through the history of geometry down to the present day. Neither do I intend to emphasize one tendency at the expense of the other. But of this fact I feel clearly and absolutely certain, that a divorce between the two-such as has existed in some of our great mathematical schools-is wholly unnatural, and tends sadly to retard the efficiency of both. What we are slowly but surely learning in this country, owing to the pressure of foreign competition, is that education and theory are needed in all branches of practical life, if we are to maintain our industrial position. But it must be education and theory which is sympathetic to practise, can indeed be wedded to it, and takes upon itself no cynical and superior airs. When we compare on the one side the vast amount of mathematical talent out of touch with all human needs, and on the other the amount of practice which limps along for want of theoretical support, we cannot but be grateful for any institution or foundation which tends to promote a better fellowship between the two. This union of theory and practice, with its offspring the applied sciences, has nowhere in recent times met with more cordial support than in the City of London. Within the last twenty years the science of engineering has been revolutionized ; from an empirical and mechanical craft engineering has been raised to the rank of a learned profession. The introduction of theory into engineering practice has been largely due to the progress of modern geometry and the geometrical methods of calculation.

Problems, which when clothed in mathematical symbols only served to appal the practical man, became intelligible to him when hieroglyphics were replaced by curves upon the drawing-board. The success of this particular union of practice and theory is largely, I believe, due to the choice of a geometrical method, to the recognition that form and figure are more easily realizable by the average mind than symbol and numeric quantity.

I have referred to the union of theory and practice which has been so largely realized of late years in engineering instruction because it offers us a striking example, not only of the success of theory as applied to practice, but also of the manner in which that theory, in order to be successful, must be applied. The theory does not need to be superficial, but it must be of a kind which the practical man can grasp; the calculations must be made 
in a form which appeals to his imagination, and in the particular sciences preliminary to the engineering profession this has been largely done by the aid of geometrical and graphical methods. Twenty years ago these methods were scarcely discovered, or the few known were neglected or scouted. To-day the most scientific Government in Europe permits the calculations and plans of the largest engineering structures which are submitted for its approval to be made by purely graphical processes. Here, then, we have an instance of theory placing at the disposal of practice one of the most efficient instruments of modern calculation and investigation, and this, indeed, is peculiarly the light in which, owing to early tradition and present needs, geometry ought, I think, to be dealt with at Gresham College. I do not mean by this that the sympathies of the City should be entirely with what we may term the Egyptian as contrasted with the Greek view of science, but solely that the City has already entered upon the labour of reconciling theory and practice, and that for a long time to come more efficient work might probably be done in this College by spreading and utilizing existing knowledge than by extending the boundaries of pure theory. The Gresham lecturer will, I fully believe, best supply existing needs, if he deals rather with the applications of geometry to practical life, than if he discourses on the more complex aspects of his subject.

I have said that this seems to me consonant with the early traditions of the College. When Sir Thomas Gresham founded this College, the old mediæval conceptions of education were dying, and modern science and modern thought were in their birth-throes. The Renascence with its revival of learning had resuscitated the knowledge of the Greek geometry. But the minds of men were not content with pure theory; they were anxious to understand the laws of the physical universeastrology was being replaced by astronomy, chemistry was deposing alchemy. The old forms remained, but they were filled with a new life. Sir Thomas Gresham, indeed, when he founded bis College established his seven professorships on the lines of an old mediæval University, in which all knowledge was forced into one of the seven divisions-divinity, astronomy, geometry, music, law, physic, and rhetoric. But what a very different view the early science professors-those of astronomy and geometry-took of their subjects to what would have been possible a hundred years earlier! Geometry for them meant the application of mathematical knowledge to all the branches of physical science. It was not for them the pure theory of lines and circles and curves, but a process of calculating and investigating the facts of Nature. Thus the revival of geometry in the sixteenth and seventeenth centuries was on Egyptian rather than Greek lines. Newton, with astounding ing enuity, used geometry as his main instrument for investigating the motions of the moon and planets. The early occupants of the Gresham chairs of both geometry and astronomy were amongst the most distinguished scientific men of their time, especially interested in the application of mathematics to the problems of Nature and to the practical sides of life. Those were the days when England was building up a greater empire for itself on the other side of the world, and if you were to ask me what beyond their indomitable pluck carried our sailors and colonists over the Atlantic and Pacific in their frail and diminutive craft, I should reply, The labours of the Gresham professors of geometry and astronomy. It was they who published the first tables and manuals tor English seamen, explained and improved the compass, the sextant, and the construction of ships. Briggs, the first occupant of the chair of geometry, wrote a work entitled, "The North-west Passage to the South Sea through the Continent of Virginia," and another entitled, "Tables for the Improvement of Navigation." It was Briggs who was mainly instrumental in introducing the use of logarithms, that most wonderful feature of modern calculation, the use of which is imperative on every seaman and astronomer of to-day. His colleague in the chair of astronomy, Gunter (1619-26) drew up a table of logarithmic sines and tangents for the first timea table familiar now to every navigator and landsurveyor. He was also the first discoverer of the slide-rule, now found in every architect and engineer's office, while for long his sun-dials at Whitehall remained standard time-keepers. Gellibrand, his successor (1626-36) wrote a treatise on the variation of the magnetic needle, and an "I Epitome of Navigation" for seamen. No less active in this direction was Samuel Foster, who held the astronomy chair from 1641 to 1652 . He explained the use of the quadrant for finding position at sea, and wrote more than one work bringing home the results of theory to the seventeenth century seamen. Lawrence Rooke, who successively held the chairs of astronomy and geometry, published "Directions for Seamen going to the East or West Indies to keep a Journal." To Sir Christopher Wren, who was Gresham professor from $16,7-60$, there is no need to make any reference in the City. His practical applications of theory are well known; that he published books on navigation and the structure of ships, that he first gave a theory of the pendulum, and improved the telescope, is perhaps less generally remembered. In his days there was a scientific enthusiasm at Gresham College which we can hardly realize anywhere now. Wren, we hear, had special charge of the planet Saturn, and his colleague Rooke of Jupiter, and their observations and lectures turned on the great discoveries then being made with regard to these peerless chiefs of the solar system.

But perhaps the most brilliant of the Gresham professors was Robert Hooke, who held the chair of geometry from 1665 to 1703 . He also published "Directions for Seamen"; he delivered and afterwards published "Lectures for improving Navigation and Astronomy." But more than all he invented the watch, with the declared object of measuring time at sea, where no pendulum clock could be of service. The first account of the construction of the watch was given by the Gresham professor of geometry in his lectures at the College on "Several new Kinds of Watches for the Pocket wherein the Motion is regulated by Springs." Hooke improved also the reflecting telescope ; he invented a marine barometer, and several new kinds of lamps. He wrote a treatise on the sails of windmills. He laid the foundation of the modern science of elasticity, and made the earliest researches of scientific value on the strength of materials. After the Great Fire of London, Hooke, like his former colleague Sir Christopher Wren, presented a model for the rebuilding of the City. Indeed, it is no exaggeration to say that in the seventeenth century it was to the Gresham professors that practical men seeking help from theoretical science naturally turned.

I might, had I the time at my disposal, bring still further evidence to show that the earliest of Sir Thomas Gresham's lecturers were essentially occupied with the applications of science to practical life, and that this tradition lasted so long as the post of Gresham lecturer meant in itself one of the highest distinctions in the land. But I can only now refer to one fact from which in itself a true idea of the original activity of Gresham College might be formed. Gresham College was the cradle of the Royal Society. It was within its walls, and notably within the rooms of the professor of geometry, Lawrence Rooke, that the makers of England's earliest scientific reputation, men like John Wallis, Robert Boyle, and Lord Brouncker, together with the Gresham professors, Christopher Wren, Robert Hooke, and Sir William Petty, used to meet to cliscuss experiments, and it was at Gresham College that they received their charter of incorporation as the Royal Society in 1662.

A French traveller, who visited England in the year NO. [ IO8, vOL. 43] 
I663, and whose diary has recently been republished, gives us an account of several visits to the Royal Society's meetings at Gresham College :-

"On May 23," he writes, "I was at the Academy of Gresham, where every Wednesday an assembly is held to make a variety of experiments upon matters not yet fully understood, but which are described according to each one's knowledge, while an account of them is written out by the secretary. The President, who is always a person of quality, is seated at the top of a great square table, and the secretary at one side. The Academicians are seated on benches running round the hall. The President is Lord Brouncker, and the secretary is Mr. Oldenburg. The President has a little wooden hammer in his hand, with which he strikes the table to call to silence those who want to speak when another is speaking; thus there is no confusion or clamour.

"It was reported that salt of tartar put upon toads, vipers, or other venomous beasts caused them to die; some one said that quicksilver had the same effect ; that these animals could not live in Ireland, as they could not bear the soil, and that experiments had been made by putting them on soil brought from England along with the animals; when they thought to escape, and approached the soil of the country, they always had to turn back, and did this until they died. Further, that a branch of holly placed in a certain lake in Ireland, in such wise that a part was in the earth, a part in the water, and a part in the air, after some time-a year or thereaboutschanged its nature; the part in air remained indeed wood, but that in the water became petrified, and that in the earth metallic in character. ... In order to procure in ponds fish of all sorts which are difficult of transport, it is only necessary to carry the eggs of the fish one requires, and these will afterwards hatch out; this a lord from Ireland said he had put into practice. Further, it was noted that the germination of insects does not arise from decay; for the intestines of an animal and other parts which easily corrupt having been placed in a glass closed with cotton-wool, so that no fly or other animal could enter, but only the air could penetrate, they had been preserved for six weeks without maggot or other thing being observed. . . Bodies weighed in the air had been afterwards weighed in a very deep pit, and had been found to weigh one-sixteenth less. That bodies which sunk in water came up again when one put more water into the vessel, which proved the compression of water by water. ... Sir Robert Moray told me that the President wished to give to the public a new science of the movement of bodies in water, and so to improve the art of navigation; with this end in view he was experimenting on the ease with which bodies of diverse shapes moved through water. ... That a method of learning the difference of weight of various liquids was to weigh in them a body attached by a fine thread of silver or other metal, and the difference of the weights of this body enabled one to estimate the weights of the liquids.

"The meeting concluded with the exhibition of a number of experiments made with an air pump invented by Robert Boyle."

Some of these experiments may sound strange to modern ears trained to a more scientific view of natural phenomena; but their general drift is in the right direction, and their bearing on the needs of every-day life sufficiently obvious to warrant us in asserting that it was in Gresham College and around its professors that in the seventeenth century those interested in the practical and experimental sides of science collected. I believe that the dignity and importance of the College in its early days were largely due to its being closely in touch with the wants of practical life. I have no wish to minimize the educational value of purely theoretical science. recognize how great a factor it has been and is in the intellectual and spiritual growth of the nation. Investigations like those of Darwin and Maxwell, which appear at first sight to have no practical applications, may profoundly alter our whole view of human life, or of the physical world which surrounds it, and in doing this may modify indefinitely our practical conduct or our command of the forces of Nature.

Even geometry in its more abstruse speculations, when it transcends the space in which we live and theorizes of another, of which ours is as poorly representative as a landscape painted on flat canvas is poorly representative of the wealth of form and distance in the scene it depicts - even this abstruse geometry may some day react on practical life, by the modifications it is capable of producing in the current ideas of space and force. I recognize to the full this educational value in geometry, and in all forms of pure science; but I believe that there are other institutions-notably the great Universities-which sufficiently emphasize this side of learning. On the other hand, I think that there is a gap which Gresham College is well suited to fill, and I believe that to fill it would not be out of accordance with its early traditions. By this gap I understand the want of an institution which, while recognizing the educational value of science, would mainly devote itself to pointing out, in a popular manner, the bearing of the conclusions of modern science on practice and the applications which can be made of them to ordinary life.

In particular, it seems to me that the lectures on geometry can be made especially serviceable in this direction, if geometry be interpreted in the wide sense current in the seventeenth century, and which it retains to this day in France. The modern development of graphical and geometrical methods has placed a powerful instrument of calculation and investigation in the hands of those who have neither the time nor opportunity of learning to handle the abstruse tools of analytical mathematics. Wherever quantity of any sort has to be measured and reasoned upon, there these gecmetrical methods find their applications. Their applications are indeed so manifold that it is difficult to enumerate them : to questions of force and motion, to problems in the strength of materials, in the structure of bridges and roof-trusses, of machinery in motion, of cutting and embanking--they have been long applied, and form the basis of much of modern engineering practice. But there are other fields which would constitute more suitable topics for a Gresham lecturer. The graphical representation of statistics at once suggests itself. Mortality, trade, goods and personal traffic, furnish statistics which if dealt with in a graphical manner very often suggest conclusions which are of the greatest interest to those dealing with problems of insurance and commerce--conclusions more readily deducible from the geometrical than from the numerical representation of statistics. What may be achieved in this direction is admirably illustrated by the graphical album of trade returns published annually by the French Government. The like geometrical methods have in recent years been applied to the principles of political economy, till the theory of prices has become almost a branch of applied geometry.

But it is not alone in these very specialized subjects that we may reason geometrically. The whole field of physical science is occupied with the investigation, representation, and reasoning upon quantity', and therefore is essentially a field for the application of geometrical methods, but the bearings of physical science on practical life are too wide and too well known to be enlarged upon now. I had intended originally to take to-night some single point in this field, and explain how geometry might be used to elucidate it; but on second thoughts it seemed to me probable that the geometrical preliminaries would have absorbed all the time at my disposal, and that ac-

NO. I IO8, VOL. 43] 
cordingly I might with more advantage lay general stress on the importance of the practical applications of geometry. In doing this, I have possibly had the future of Gresham College more in view than my own candidature for the lectureship in geometry.

But I believe that, quite apart from the present election, the College has a future worthy of its earliest days, and that, not improbably, this future, if in another field, will still lie within the same broad lines that the City has already laid down for itself in the matter of technical education, the motto of which $I$ take to be: Practice enlightened by theory, theory guided by practical needs. Work on such lines as these, accompanied by the expansion due to modern scientific requirements, would, I fully believe, restore the College to something like its old position among the teaching bodies of London, and reverse the judgment of that Cambridge historian of mathematics who has recently remarked that, "with the beginning of the eighteenth century, an appointment at Gresham College ceased to be a mark of scientific distinction."

\section{THE PHOTOGRAPHIC CHART OF THE HEA VENS.'}

THE publication of the fifth fasciculus brings us within reasonable distance of the actual commencement of the celestial chart, and the centre of interest is shifted from the theoretical speculations which have characterized the earlier publications to the more practical details suggested by the employment of the photographic instruments in those Observatories which are now equipped for the undertaking.

After three years of anxious organization, Admiral Mouchez sees the goal for which he has laboured so strenuously well in view. We may offer him our congratulations on what may be regarded as the completion of the first. but not the least arduous, portion of the task he has undertaken. He has succeeded in binding together, with a common aim and with unity of purpose, the astronomical energies of various nationalities, and, mainly through his exertions, the reputation of many $\mathrm{Ob}$ servatories stands pledged to complete the scheme which he has originated.

That great tact and delicacy have been necessary to carry the initial proceedings to a successful issue will be readily granted. Possessed as the French were with the typical photo-telescope, it would have been possible-nay, it might have been expected - that the Paris astronomers would have conducted a series of inquiries and experiments which would have enabled them to insist upon the exact arrangement of many details, and thus practically to exclude the judgment and participation of those $\mathrm{Ob}-$ servatories whose equipment was less complete. But, with a delicacy which some might think almost to border on indifference, the French astronomers have nowhere taken advantage of the early possession of their phototelescope to enable them to anticipate the researches of their collaborateurs. This policy of affording a fair start to the many participants will prevent any step of real practical importance in the actual photographing of the zones being undertaken till after another general Conference has met and deliberated. The invitations for this Conference have been issued for March next.

But if the French astronomers have been willing to efface themselves to some extent, in order to advance the scheme in which they are so much interested, it must be admitted with gratitude that they have been at all times willing to submit to various astronomers negatives, taken with the Paris instrument, for the discussion and decision

I "Bulletin du Comité International Permanent pour l'Exécution Photographique de la Carte du Ciel." Cinquième fascicule. (Paris: GauthierViliars et Fils, 189o.)

$$
\text { NO. I IO8, VOL. 43] }
$$

of questions of the first importance. In this connection we may notice the valuable discussion on photographic images, and the accuracy of their measurement at considerable distances from the centre, due to Prof. Bakhuyzen. To the same astronomer, and again employing materials placed at his disposition by the Paris authorities, is due a valuable paper on the actual measurement and determination of the co-ordinates of $34 \mathrm{I}$ stars, with the comparison, wherever possible, with meridian observations; thus affording a practical measure of the accuracy likely to be attained in the catalogue places deduced from the measured negatives.

These and other inquiries of scarcely less interest and importance have appeared in the earlier fascicules published under the auspices of the Permanent Committee. One of the aims of this Committee appears to have been to collect in one convenient summary the whole of the literature which bears on the question of the photographic chart. Consequently, many papers which have appeared from time to time in other periodicals are reproduced here, either complete, or as abstracts. To these papers no reference need now be made. It will, however, be a matter of sincere regret to many astronomers, that no account is given of the experiments which, it is understood, have been carried out by Dr. Eder, under the auspices of the Committee. These experiments were undertaken with the view of determining the best method of preparing and developing the sensitized plates to be used in the chart. The results of an investigation conducted by so able and experienced a photographer as Dr. Eder were expected with considerable interest; and the omission of any reference to his results is the more to be regretted, since it was announced in September I889, that the experiments were complete, and that the manuscript giving details would be forwarded to Paris in a fortnight. We may hope that the absence of any reference to Dr. Eder's work is caused by a simple delay, and does not indicate an abandonment of the inquiry.

Among the original papers which add an importance to the fifth fascicule are two contributed by the Astronomer-Royal, and which mark a distinct progress in the settlement of the preliminary details. In the first of these are reported the conclusions arrived at by a Committee appointed to consider the method of choosing the co-ordinates of the centres of consecutive plates. The problem the Committee had to solve was, how to fit, with the least possible loss of plates, and with the greatest convenience to the observer, a series of square plates to the concave surface of a sphere. It is evident that, as the declination increases, very different angles of right ascension are covered by the plate, and that even on the same plate, since the side covers $2^{\circ}$, the top and bottom of the plate will not occupy the same arc of right ascension. At $45^{\circ}$ declination, the northern edge of the plate will correspond to six minutes more of R.A. than the southern, and of course, at greater declinations, the want of uniformity in this respect becomes more and more marked. The difficulty is not diminished by a decision of the Permanent Committee, that a second series of negatives should be taken, in which a corner of the plate in the first series should be made to coincide with the centre of a plate in the second series. Under these circumstances, the Committee submit two slightly different schemes. In either of these methods the centre of the plate will be made to correspond to the beginning of a minute of right ascension.

But to maintain this convenient rule, and at the same time adhere rigorously to the recommendations of the Conference, it would be necessary to arrange the zones photographed in such a manner that the breadth of the zone should be such that an arc of $2^{\circ}$ of a great circle covers an even number of minutes of R.A. The Committee therefore contemplate the possibility of slightly relaxing the decisions of the Conference, and to so arrange 